UNIVERSITE DE LAUSANNE - FACULTE DE BIOLOGIE ET DE MEDECINE

Département de Médecine

Service de Gériatrie et Réadaptation Gériatrique

\title{
New Diagnoses of Dementia Among Older Patients Admitted to Postacute Care
}

\section{THESE}

préparée sous la direction du Professeur Christophe J.Büila avec la collaboration de la Doctoresse Laurance Seematter-Bagnoud et présentée à la Faculté de biologie et de médecine de l'université de Lausanne pour l'obtention du grade de

\section{DOCTEUR EN MEDECINE}

$$
\text { par }
$$

Michele FERRETTI

Médecin diplômé de la Confédération Suisse

Originaire de Bedigliora (TI)

Lausanne

2010 


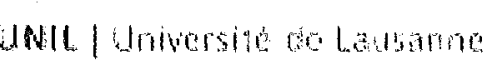

Fonthe de hobole

en medoente

Ecole Doctorale

Doctorat en médecine

\section{Imprimatur}

Vu le rapport présenté par le jury d'examen, composé de

Directeur de thèse Monsieur le Professeur Christophe Büla

Co-Directeur de thèse

Expert

Monsieur le Professeur associé Joseph Ghika

Directrice de l'Ecole Madane le Professeur Stephanie Clarke doctorale

la Commission MD de l'Ecole doctorale autorise l'impression de la thèse de

Monsieur Michele Ferretti

intitulée

New diagnoses of dementia among older patients admitted to postacute care

Lausanne, le 19 octobre 2010

$$
\text { pour Le Doyen }
$$

de la Faculté de Biologie et de Médecine

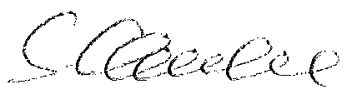

Madame le Professeur Stephanie Clarke Directrice de l'Ecole doctorale 


\section{Rapport de synthèse}

Introduction : bien que la prévalence des syndromes démentiels soit élevée chez les personnes âgées hospitalisées et qu'une proportion non négligeable échappe au diagnostic, la littérature ne fournit que peu de données chez les patients admis en milieu de réadaptation post-aigu. L'objectif principal de ce travail était de déterminer la prévalence des démences, ainsi que la proportion de démences non diagnostiquées dans une population admise dans un centre de réadaptation gériatrique. Ensuite, nous nous sommes intéressés à identifier les caractéristiques des patients associées à une démence non-détectée.

Méthode : nous avons utilisé les données de tous les patients âgés de 70 ans et plus admis durant 3 ans dans l'unité de réadaptation du service de gériatrie et réadaptation gériatrique, Centre Hospitalier Universitaire Vaudois, en excluant les patients décédés pendant l'hospitalisation. Lors de l'admission, des données sociodémographiques, médicales, ainsi que des données concernant le status fonctionnel et mental sont récoltées systématiquement. Par ailleurs, les dossiers des patients ont été examinés pour en extraire les informations quant aux performances cognitives (mini-Mental State Exam, MMSE) et au diagnostic de sortie.

Résultats: un diagnostic de démence figurait dans la lettre de sortie de 425 des 1764 patients (24.1\%), plus de la moitié présentant une démence de type Alzheimer. Pour 301 de ces 425 patients $(70.8 \%)$, la démence avait été diagnostiquée durant le séjour de réadaptation. La proportion de démences non-détectées auparavant était plus élevée chez les patients provenant des services de chirurgie/orthopédie que de médecine interne (74.8\% vs $65.8 \%, \mathrm{p}=.42)$. Les patients non diagnostiqués comme déments étaient plus âgés, vivaient plus souvent seuls et avaient de meilleures performances fonctionnelles et cognitives que ceux chez qui le diagnostic avait été posé auparavant. Notamment, un tiers d'entre eux avait un score normal au MMSE. Une analyse multi-variée a mis en évidence deux facteurs prédisposant à la non-détection : l'âge (Odds Ratio (OR) : 2.4 pour le groupe d'âge 85 ans et plus par rapport aux plus jeunes, 96\% CI : 1.5-4.0, p=.001) et le score au MMSE (OR : 5.9 lors d'un MMSE normal à l'admission, 96\%CI : $2.7-12.7, \mathrm{p}<.001)$

Conclusion et perspectives : cette étude montre qu'environ un quart des patients admis en réadaptation gériatrique souffre de démence, et que cette pathologie n'est pas reconnue chez les trois-quarts d'entre eux. Ces résultats soulignent la nécessité d'un dépistage systématique des troubles cognitifs chez les patients âgés. En effet, en l'absence de détection, ces patients ne peuvent bénéficier d'une prise en charge approprié, incluant non seulement des mesures médicales et pharmacologiques, mais surtout l'information du patient et des proches, dans le but de maintenir une qualité de vie acceptable du patient ainsi que de prévenir l'épuisement des proches et des soignants. Cette étude incite aussi à être attentif aux signes évocateurs de troubles cognitifs lors de l'interprétation du test MMSE, car un score dans les limites de la norme ne permet pas d'exclure une démence. 


\title{
New Diagnoses of Dementia Among Older Patients Admitted to Postacute Care
}

\author{
Michele Ferretti, MD, Laurence Seematter-Bagnoud, MD, MSc, Estelle Martin, PhD, and Christophe J. Buila, MD
}

Objectives: To determine the prevalence of dementia and the proportion of undiagnosed dementia in elderly patients admitted to postacute care, and to identify patients' characteristics associated with undiagnosed dementia.

\section{Design: Cross-sectional study.}

Setting: Academic postacute rehabilitation facility in Lausanne, Switzerland.

Participants: Patients $(N=1764)$ aged 70 years and older.

Measurements: Data on socio-demographic, medical, functional, and affective status were collected upon admission. Data on cognitive performance (MiniMental State Exam [MMSE]), and cognition-related discharge diagnoses were abstracted through a structured review of discharge summaries.

Results: Overall, 24.1\% (425/1764) patients had a diagnosis of dementia, most frequently secondary to Alzheimer's disease $(260 / 425,61.2 \%)$. Among dementia cases, $70.8 \%$ (301/425) were newly diagnosed during postacute stay. This proportion was lower among patients referred from internal medicine than from orthopedic/surgery services $(65.8 \%$ versus $74.8 \%$, $P=.042$ ). Compared to patients with already diagnosed dementia, those newly diagnosed were older, lived alone more frequently, and had better functional status and MMSE score at admission (all $P<.05)$. In multivariate analysis, previously undetected dementia remained associated with older age $(\mathrm{OR}=2.4$ for age 85 years and older, $95 \% \mathrm{Cl} 1.5-4.0$, $P=.001)$ and normal MMSE at admission $(O R=5.9$, $95 \% \mathrm{Cl} 2.7-12.7, P<.001)$.

Conclusion: Dementia was present in almost a fourth of elderly patients referred to postacute care, but was diagnosed in less than a third before admission. Oldest old patients appear especially at risk for underrecognition. These results emphasize the high diagnostic yield of systematic cognitive assessment in the postacute care setting to improve these patients' management and quality of life. ( $\mathrm{Am}$ Med Dir Assoc 2010; 11: 371-376)

Keywords: Elderly; postacute care; dementia; detection
Dementia is frequent among older persons, with a prevalence varying according to age and care setring. In this regard, highest prevalence (up to 70\%) has been observed in studies conducted in the assisted living and long-term care population, ${ }^{1-5}$ but surprisingly few data are available in patients undergoing postacute care. One study reported that $40 \%$ of older

Service of Gerlatric Medicine and Gerlatric Rehabilitation, Department of Medicine, University of Lausanne Medical Center (CHUV), Lausanne, Switzerland (M.F, L.S.-B., E.M., C.J.B.); Institute of Social and Preventive Medicine, University of Lausanne, Lausanne, Switzerland (L.S.-B.)

The authors have no conflicts of interest.

Address correspondence to Laurence Seematter-Bagnoud, MD, MSC, Service of Geriatric Medicine and Geriatric Rehabilitation, CHUV, CUTR Sylvana, Ch de Sylvana \# 10, CH-1066 Epalinges, Switzerland. E-mail: Laurence. Seematter-Bagnoud@chuv.ch

Copyright (2010 American Medical Directors Association DOl:10.1016/j.jamda.2009.10.002 patients admitted to postacute rehabilitation had dementia, ${ }^{6}$ whereas around $60 \%$ of patients admitted to geriatric continuation care units were found to be cognitively impaired in another study. ${ }^{7}$ Similarly, little is known about dementia detection rate in the postacute care setting, as well as about characteristics of patients admitted to this setting with unrec. ognized dementia. Studies conducted among outpatient populations report that $30 \%$ to $70 \%$ of dementia cases are not recognized. ${ }^{8-12}$ The proportion of undetected dementia is also high in other settings, reaching $63 \%$ in a study of older medical inpatients, ${ }^{1.3}$ and $58 \%$ in residents of assisted living facilities, a setting closer to postacute care. ${ }^{3}$ Several barriers concur to poor detection of dementia by health professionals, including insufficient clinical training, time constraints, absence of routine screening procedures, and the still widely spread assumption that cognitive decline is part of normal ag. ing. Although these barriers might be less prevalent among professionals specifically dedicated to geriatric care, this has not been widely investigated. In particular, the diagnostic 
yield of a systematic cognitive assessment in postacute care remains unknown.

Early recognition of cognitive impairment and diagnosis of dementia are critical steps necessary to initiate appropriate management, including patient and proxy counseling, medication review, prescription of specific pharmacological treatment, as well as caregiver supportive measures. These measures, aiming at preserving patient function and quality of life, preventing caregiver depression and burn-out, and delaying or ayoiding institutionalization, ${ }^{14-18}$ are especially relevant for older patients admitted to postacute care and rehabilitation, most of whom are likely to return to previous living conditions.

The aims of the study were to determine the prevalence of dementia and the proportion of patients diagnosed with dementia during postacute care stay. An additional objective was to investigate paticnts' characteristics associated with previously undetected dementia.

\section{POPULATION AND METHODS}

Eligible participants were patients aged 70 years and older consecutively admitted from an acute hospital ward to postacute care in an academic medical center over a 3-year period $(\mathrm{N}=2130)$. Patients who died during their stay $(\mathrm{N}=77)$ were excluded. In case of multiple admissions during the study period ( $N=289$ ), only the first stay was considered, leaving a final sample of 1764 patients.

Sociodemographic and medical data were systematically collected for each patient at admission. Performance in basic Activities of Daily Living (ADL) were systematically evaluated by nursing staff within 48 hours of admission using Katz basic ADL scale. ${ }^{19}$ Cognitive and affective status were assessed by the physician in charge of the patient using Folstein's Mini-Mental State Examination (MMSE), ${ }^{20}$ and Yesavage's Geriatric Depression Scale (GDS) short-form, ${ }^{21}$ respectively, Referring service was identified from the administrative hospital database.

Data about cognition-related diagnosis were abstracted by a physician through a systematic structured review of discharge summaries. Discharge summary is mandatory for each hospital stay and should contain all information relevant for the primary care physician to ensure the continuity of care. Diagnoses were based on the National Institute of Neurological and Communicative Disorders and Stroke and Alzheimer's Disease and Related Disorders Association (NINCDS-ADRDA) criteria for Alzheimer disease, ${ }^{22}$ the State of California Alzheimer's Disease Diagnostic and Treatment Centers (ADDTC) criteria for vascular dementia, ${ }^{23}$ and Newcastle's criteria for Lewy bodies dementia. ${ }^{24}$ Quality of data abstraction was assessed through testretest of a landom sample $(N=50)$ of discharge summaties by a second independent physician, blinded to the first teviewer assessment. Interrater agreement on dementia diagnosis was $92 \%$ (kappa $0.88, P<.001)$. The study was approved by the university review board and paticnts provided oral informed consent.

For the statistical analyses, the sample was divided into 2 groups according to whether a diagnosis of dementia was listed in the discharge summary or not. The group of patients with dementia included patients diagnosed with dementia attributable to Alzheimer's disease, vascular or mixed dementia, dementia with Lewy bodies, fronto-temporal dementia, as well as toxic (eg, alcohol-related) and unspecified dementia. Patients presenting with delirium were classified as nondemented, unless there was a clear history from proxies and/or the primary care physician of previous cognitive de. cline with memory impairment highly suggestive of incipient, undiagnosed dementia. This occurred in 47 cases, who were classiffed as having unspecified dementia. All other patients, including those with cognitive impairment not fulfilling dementia ctiteria (mild cognitive impairment, pure delirium, cognitive impairment related to depression) were considered as patients without dementia.

Characteristics of patients with and without dementia were compared using the Pearson chi-squared test for categorical variables and the Student $t$ test for continuous variables. Then, a multivariate model examined which of these characteristics werc independently associated with dementia. The following covariates were entered in the model, based on a priori hypotheses: age, gender, formal home care before admission, living alone, basic ADL performance at admission, and MMSE score of 24 or higher.

Similar bivariate and multivariate analyses were performed in the subgroup of subjects with dementia, to compare characteristics of subjects diagnosed during their stay with those of subjects already diagnosed before their stay. The same set of covariates previously mentioned was used for adjustment in the multivariate analysis.

Statistical analyses were performed on Stata 10.0 (STATA Corp., College Station, TX) software.

\section{RESULTS}

Characteristics of the study population and their comparisons in patients with and without dementia are displayed in Table 1 . Overall, $24.1 \%$ of the patients were discharged with a diagnosis of dementia. The most frequent diagnosis was dementia attributable to Alzheimer's disease (61.2\%), whereas mixed, vascular, and Lewy bodies dementias represented each less than $10 \%$ of the cases (Figure 1).

Compated with patients without dementia, those with dementia were older, more frequently received formal home care before their admission, and had lower performance in basic ADLs at admission. These patients were less frequently admitted after a hip firacture and more frequently after respiratory and cerebrovascular events. Finally, although the average MMSE score was significantly lower among patients with dementia, $25.4 \%$ still had a score in the range considered as normal in most older persons $(\geq 24)$. In multivariate analysis, abnormal MMSE (adjusted odds ratio [adjOR]: 16.6, 95\% confidence interval [CI] 12.5-22.1, $P<.001$ for an MMSE score $<24$ ), age 85 years and older (adjOR: $1,4,95 \% \mathrm{Cl}$ $1.1-1.9, P=.014$ ), lower functional status (adjOR: 0.9 per each additional point at Katz's basic ADL scale, 95\% CI: $0.8-0.9, P=.001$ ), and male gender (adjOR:1,4,95\% CI $1.0-1.9, P=.041$ ) remained significantly associated with dementia (data not shown). 
Table 1. Baseline Characteristics of the Total Population and Comparison of Sudy Grouts

\begin{tabular}{|c|c|c|c|c|}
\hline \multirow[t]{2}{*}{ Characteristics } & \multirow[t]{2}{*}{ Total $(N=1764)$} & \multicolumn{2}{|l|}{ Dementia } & \multirow[t]{2}{*}{$P^{*}$} \\
\hline & & Yes $(N=425)$ & No $(N=1339)$ & \\
\hline Age, $y$, mean $t S D$ & $82.3 \pm 6.7$ & $84.4 \pm 6.2$ & $81.6 \pm 6.7$ & $<.001$ \\
\hline Women, \% & 69.6 & 66.1 & 70.7 & .072 \\
\hline Living alone, \% & 60.2 & 57.6 & 61.1 & .200 \\
\hline Formal home care before admission, \% & 53.9 & 67.5 & 48.4 & $<.001$ \\
\hline $\begin{array}{l}\text { BADL score at admission,t mean }+ \text { SD } \\
\text { Main acute diagnosis, } \%\end{array}$ & \multicolumn{3}{|c|}{ Main acute diagnosis, $\%$} & $<.001$ \\
\hline - hip fracture & 24.0 & 22.3 & 24.6 & .376 \\
\hline - osteoarticular conditionsł & 21.4 & 13.7 & 24.0 & $<.001$ \\
\hline - cardiovascular disease & 12.9 & 9.7 & 14.0 & .038 \\
\hline - respiratory disease & 6.5 & 9.1 & 5.6 & .019 \\
\hline - cerebrovascular disease & 5.6 & 8.6 & 4.6 & .006 \\
\hline - gastrointestinal disease & 4.9 & 5.1 & 4.8 & .814 \\
\hline - miscellaneous & 19.6 & 25.9 & 17.6 & $<.001$ \\
\hline Depressive symptoms, $\$ \%$ & 16.5 & 16.0 & 16.8 & .700 \\
\hline MMSE score, $\|$ mean $\pm S D$ & $24.6 \pm 5.1$ & $19.1 \pm 5.5$ & $26.3 \pm 3.5$ & $<.001$ \\
\hline Abnormal MMSE, $9 \%$ & 28.0 & 74.6 & 13.3 & $<.001$ \\
\hline
\end{tabular}

MMSE score $\geq 24$ is considered as within normal range.

* Chi-square test (categorical variables) or Student $t$ test (continuous variables).

$\uparrow$ Basic Activities of Dally Living. ${ }^{19}$ Include bathing, dressing, using the tollet, transferring between bed and chair, maintaining continence, feeding. Scores range from 0 to 6 , with higher scores indicating higher function.

\$ Osteoarticular conditions include medical and surgical diseases excluding hip fracture.

$\S$ Defined as a score of 6 or more at the Geriatric Depression Scale, short form ${ }^{21}$ (15 items).

|| Folstein's Mini Mental Status Examination. Scores range from 0 to 30 , with higher score indicating higher cognitive function ${ }^{20}$

II Defined as a score $<24$ on Folstein's Mini-Mental State Examination. ${ }^{20}$

Among the 425 patients diagnosed with dementia, $70.8 \%$ (301/425) had not been diagnosed before the postacute stay. Table 2 compares their characteristics with those of patients $(\mathrm{N}=124)$ whose dementia was previously diagnosed. Patients diagnosed during postacute stay were older, lived alone more frequently, and had better functional as well as mental performances at admission. Interestingly, almost a third $(32.5 \%)$ of patients diagnosed during postacute care had an MMSE score of 24 or higher at admission to postacute rehabilitation. Finally, the proportion of demented patients whose diagnosis was made during rehabilitation was somewhat lower anong patients referred from internal medicine than surgical services (Figure 2).

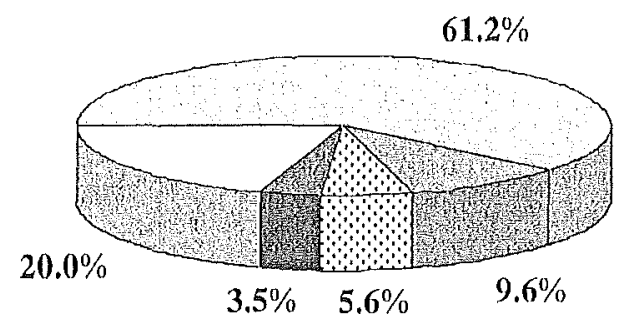
$\square$ Alzheimer's Discasc $(\mathrm{N}=260)$
国 Mixed $(\mathrm{N}=41)$
Đ Vascular $(\mathrm{N}=24)$
回 Lewy bodies $(\mathrm{N}=15)$
$\square$ Miscellaneous ( $N=85$ )

Fig. 1. Etiology of dementia $(N=425)$. Miscellaneous category includes fronto-temporal dementias, toxic dementia, and unspecified dementias.
In mulcivariate analysis (Table 3 ), age 85 years and older (adjOR: $2.4,95 \%$ CI 1.5-4.0, $P=.001$ ), and an MMSE score of 24 or higher at admission to postacute rehabilitation (adjOR: 5.9, 95\% CI 2.7-12.7, P <.001) remained independently associated with a previously undetected dementia. A variable defuning the referring service was also included in a stepwise regression analysis, but did not remain in the model.

A stratified analysis showed that, among patients with MMSE scorc lower than 24 at admission, the proportion who remained undiagnosed until their admission to postacute rehabilitation reached $75 \%$ in paticnts aged 85 years and older, compared with $52 \%$ in those younger than 85 years $(P<.001)$. However, interaction between MMSE and age did not reach statistical significance when tested in the multivariate model.

\section{DISCUSSION}

This study found that a fourth of older patients admitted to postacute care had a diagnosis of dementia, two thirds of which were previously unknown. To our knowledge, this is the first study to document the magnitude of the current gap in dementia diagnosis among older patients admitted to postacute-care rehabilitation. These observations have sev. eral implications.

First, these results emphasize the need to implement a systematic cognitive screening in this setting when caring for similar populations. Ironically, the highest levels of undetected dementia have been found in populations with very high prevalence of dementia. For example, it has been documented that about two thirds of cognitively impaired residents of assisted living facilities had not been properly diagnosed. ${ }^{3,5}$ Missing a dementia diagnosis is likely to delay 
Table 2. Comparison between Patients with Prewiously Diagnosed Dementia and Those Diagnosed with Dementia during Postacute Care Stay

\begin{tabular}{llll}
\hline Characteristics & \multicolumn{3}{l}{ Dementia diagnosed before the postacute stay? } \\
\cline { 2 - 4 } & Yes $(N=124)$ & No $(N=301)$ & $84.9 \pm 6.1$ \\
\hline Age, $y$, mean \pm SD & $83.3 \pm 6.6$ & 68.4 & .015 \\
Woman, \% & 60.5 & 66.0 & .115 \\
Formal home care before admission, $\%$ & 71.1 & 60.9 & .315 \\
Living alone, \% & 49.6 & $2.3 \pm 1.7$ & .033 \\
BADL at admission, $\dagger$ mean \pm SD & $1.8 \pm 1.5$ & 14.4 & .004 \\
Depressive symptoms, $\% \%$ & 20.0 & $20.2 \pm 5.0$ & .195 \\
MMSE score, 5 mean $\pm S D$ & $16.3 \pm 5.7$ & 32.5 & $<.001$ \\
MMSE score $\geq 24, \%$ & 9.6 & & $<.001$
\end{tabular}

MMSE score $\geq 24$ is considered as within normal range.

* Chi-square test (categorical variables) or Student $t$ test (continuous variables).

† Basic Activities of Daily Living. ${ }^{19}$ Include bathing, dressing, using the toilet, transferring between bed and chair, maintaining continence, feeding. Scores range from 0 to 6 , with higher scores indicating higher function.

₹ Defined as a score of 6 or more at the Geriatric Depression Scale, short form ${ }^{21}$ (15 items).

$\S$ Folstein's Mini Mental Status Examination. Scores range from 0 to 30 , with higher score indicating higher cognitive function. ${ }^{20}$

interventions aimed at improving patients' and caregivers' quality of life. Second, these results also highlight the potential for better cognitive assessment upstream the admission to postacute care. These findings add to previous observations ${ }^{13}$ showing the low detection rate of cognitive problems in the acute setting. ${ }^{25}$ Improving the diagnostic process during the acute stay could certainly benefit the patient, for instance in decreasing the risk of subsequent delirium occurrence in the postacute setting. ${ }^{26}$ Finally, these results are important because they contribute to better delineate the adequate diagnostic competencies (including formal cognitive assessment) and resources that must be available in postacute care setting to better address the multiple needs of these patients.

This study also extends previous knowledge in showing that the oldest-old patients are particularly at risk of remaining undiagnosed. The association between older age and underrecognition of dementia has not been previously described in the postacute care setting. Interestingly, this association was not found in a study in assisted living facilities ${ }^{4}$ and has been inconsistently observed in studies conducted among community-dwelling and primary care older popula-

\section{Proportlon of demented pationts}

with unknown diagnosls $(\%)$

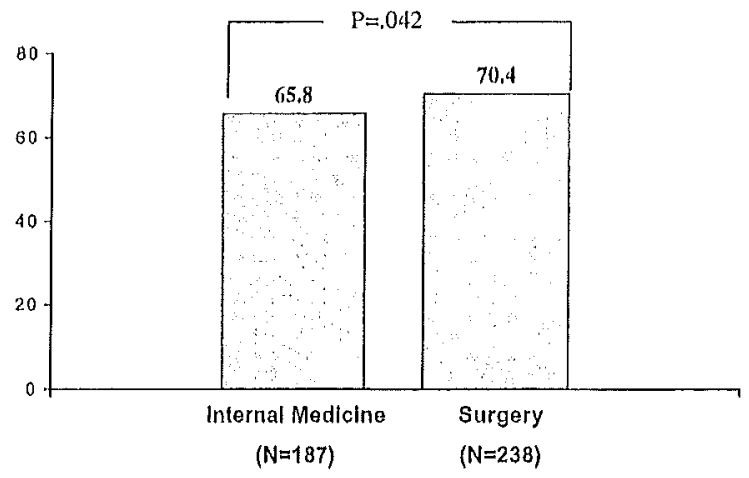

Fig. 2. Proportion of demented patients with unknown diagnosis before postacute rehabilitation stay, by type of referring service. "Surgery" category includes general surgery, traumatology, orthopedics, vascular surgery, and so forth. tions, ${ }^{8,11,12,27}$ but has also been reported in a study among acute medical inpatients. ${ }^{28}$ Most likely, underrecognition in the oldest-old patients relates to the still widespread belief of a normal age-related decline in mental performances. ${ }^{29}$ In addition, these patients might also be at increased risk for underrecognition because the usual barriers to diagnosis might seem especially relevant to physicians caring for these frail patients. Physicians' skepticism about the benefits of dementia interventions and pharmacological treatments ${ }^{30}$ or their perceived lack of time and/or skills to diagnose dementia ${ }^{31}$ are likely to make them even more reluctant to add further diagnostic burden in these already complex patients. Systematic screening could help to address the influence of age on dementia underdiagnosis.

A relatively surprising finding is the significant association between male gender and prevalent dementia in this population. Possibly, this finding results from a selection bias that makes older men less likely to be discharged from acute to postacute care because they more frequently benefit from a spouse caregiver than women of similar age. In this sample, however, men remained significantly less likely to live alone and to receive in-home care services than women, even though they were younger (data not shown). Although multivatiate analysis adjusted for these differences, one cannot exclude residual confounding. An alternative explanation is that a dementia diagnosis was more frequently made in men because the additional information necessary to assess this diagnosis (eg, repercussion of cognitive impairment on ADLs)

Table 3. Characteristics of Demented Patients Associated with a Neww Diagnosis of Dementia

\begin{tabular}{lllr}
\hline Characteristic & Adjusted OR $^{*}$ & $95 \% \mathrm{Cl}$ & $P$ value \\
\hline Age $>85$ years & 2.4 & $1.5-4.0$ & .001 \\
MMSE score $\geq 24 t$ & 5.9 & $2.7-12.7$ & $<.001$ \\
\hline
\end{tabular}

$\mathrm{Cl}$, confidence interval.

* OR: Odds ratio from stepwise multivariate analysis adjusted for age, gender, formal home care before admission, living alone, depressive symptoms, basic ADL performance at admission, and MMSE score $\geq 24$.

† MMSE: Mini Mental State Exam. Scores range from 0 to 30 with higher scores indicating better cognitive function. ${ }^{20}$ 
was more frequently available from a proxy living with the patient. This hypothesis is supported by the observation of a higher proportion of women among patients who were diag. nosed with cognitive impairment but no dementia (data not shown). Future studies in the postacute care setting should further investigate this issue.

Finally, this study emphasizes the limitation of the MNSE as a screening tool in this population: almost a fourth of previously undiagnosed subjects scored above the traditional cut-off used to define the presence of significant cognitive impairment, corresponding to a sensitivity of $74 \%$, lower than the expected $80 \%$ to $90 \%$. ${ }^{2}$ These results highlight the importance to keep a low threshold for suspecting cognitive problems and dementia in older subjects undergoing postacute rehabilitation, even when MMSE performance might be considered as within the normal tange. Interestingly, our results show that of 100 patients with a diagnosis of dementia and a normal MMSE score, 65 scored 24 or 25 points at MMSE.

A main strength of this study lies in its latge sample and the inclusion of consecutive patients resulting in a decreased risk of selection bias, as well as the completeness of data. For instance, MMSE information was missing in only 57 patients $(2.8 \%)$, principally because of a patient's refusal or impossibility to execute several items (poststroke status, deafness, foreign language, or illiteracy).

This study has some limitations: information about cognitive diagnosis is based on discharge summary. In particular, no additional follow-up was performed with proxies or primary care physicians to collect information on subsequent diagnoses in patients with delitium. Only $6.4 \%$ of the patients were considered to have delirium, alone or superimposed on dementia, a significantly lower figure than those reported in studies that specifically evaluated the prevalence of delirium in similar populations. ${ }^{26,32}$ Systematic screening for delirium would likely have resulted in higher figures. ${ }^{25}$ However, potential misclassification of these subjects in the nondemented group likely resulted in underestimating the rate of both dementia diagnosis and detection.

An additional limitation is the reliance on discharge summary to categorize patients with diagnosed and undiagnosed dementia. Although unlikely, it remains possible that detected dementia was not documented in some patients. Highlighting this gap is nevertheless important, as discharge summaries should include all information that is necessary for the primary care physician to ensure appropriate followup. The absence of such important information will surely preclude further appropriate management of the patient.

\section{CONCLUSION}

This study highlights the gap in dementia detection in postacute care and underlines the particular risk of underrecognition in the oldest-old. Furthermore, results provide important information in showing poor dementia detection in patients with a normal screening test. Overall, these findings emphasize the high diagnostic yield of systematic cognitive screening in elderly patients admitted to a postacute setting.

Increasing dementia recognition is an essential step toward the overall goal of improving the management of affected patients and increasing support to their caregiver, Earlier interventions could not only contribute to better prevent or delay nursing home admission and decrease related health care costs, but are likely to improve qualicy of life in both patients and caregivers.

\section{REFERENCES}

1. Graham JE, Rockwood K, Beattie BL, et al. Prevalence and severity of cognitive impairment with and without dementia in an elderly popula. tion. Lancet 1997;349:1793-1796.

2. Boustani $M$, Peterson $B$, Hanson $L$, et al. Screening for dementia in primary care: A summary of the evidence for the US Preventive Services Task Force. Ann Intern Med 2003; 138;927-937.

3. Magsi H, Malloy T. Underrecognition of cognitive impairnent in assis. ted living facilities. J Am Geriatr Soc 2005;53:295-298.

4. Maust DT, Onyike CU, Sheppard JM, et al. Predictots of caregiver unawareness and nontreatment of dementia among residents of assisted living facilities: The Maryland Assisted Living Study. Am J Geriatr Psychiatry 2006;14:668-675.

5. Macdonald AJ, Carpenter GI. The recognition of dementia in "nonEMI" nursing home residents in South East England. Int J Geriatr Psychi. atry 2003;18:105-108.

6. Shah DC, Evans M, King D. Prevalence of mental illness in a rehabilita. tion unit for older adults. Postgrad Med J 2000;76:153-156.

7. Hickey $A$, Clinch D, Groarke EP. Prevalence of cognitive impairment in the hospitalized elderly. Int J Geriatr Psychiatry 1997;12:27-33.

8. Zunzunegul Pastor MV, del Ser T, Rodrlguez LA, et al [Non-detected dementla and use of the health services: Implications for primary care.]. Aran Primaria 2003; 31:581-586.

9. Valcour VG, Masaki KH, Curb JD, Blanchette PL. The detection of dementia in the primary care setting. Arch Intern Med 2000;160; 2964-2968

10. Callahan CM, Hendrie HC, Tierney WM. Documentation and evaluaHon of cognitive impairment in elderly primary care patients. Ann Intern Med 1995;122:422-429.

11. Lopponen $M$, Raiha $I$, Isoaho $R$, et al. Diagnosing cognitive impairment and dementia in primary health care-a more active approach is needed. Age Ageing 2003;32:606-612.

12. Wilkins $\mathrm{CH}$, Wilkins $\mathrm{KL}$, Meisel M, et al. Dementia undiagnosed in poor older adults with functional impairment. J Am Geriatr Soc 2007;55: $1771-1776$.

13. Joray $S$, Wietisbach V, Bula CJ. Cognitive impairment in elderly med. ical inpatients! Detection and associated six-month outcomes, Am 1 Geriatr Psychiatry 2004; 12:639-647.

14. Bianchetti A, Ranieri P, Margiotta A, Trabucchi M. Pharmacological treatment of Alzheimer's disease. Aging Clin Exp Res 2006;18:158-162.

15. Bullock R, Dengiz A. Cognitive performance in pattents with Alzheimer's disease receiving cholinesterase inhibitors for up to 5 years. Int J Clin Pract 2005;59:817-822.

16. Gauthier SO. Alzheimer's disease: The benefits of ently treatment. Eur f Neurol 2005;12:11-16.

17. Sano $M, W$ llcock $G K$, van $B B$, Kayanagh $S$. The effects of galantamine treatment on caregiver time in Alzheimer's disease. Int ] Geriatr Psychiatry $2003 ; 18: 942-950$.

18. Mittelman MS, Haley WE, Clay OJ, Roth DL. Improving caregiver wellbeing delays nursing home placement of patients with Alzheimer discase. Neurology 2006;67:1592-1599.

19. Katz S. Assessing self-maintenance: Activities of daily living, mobility, and instrumental activitics of daily living. J Am Geriatr Soc 1983;31; 721-727.

20. Folstein MF, Folstein SE, McHugh PR. "Mini-mental state": A practical method for grading the cognitive state of patients for the clinician. J Psychiatr Res 1975;12:189-198.

21. Sheikh J, Yesavage ]A. Geriatric Depression Scale (GDS): Recent evi. dence and development of a shorter version. Clin Gerontol 1986;5; $165-173$. 
22. McKhann G, Drachman D, Folstein $M$, et al. Clinical diagnosis of Alz. heimer's disease: Report of the NINCDS-ADRDA Work Group under the auspices of Department of Health and Human Services Task Force on Alzheimer's Disense. Neurology 1984;34:939-944.

23. Chui HC, Victoroff JI, Margolin D, et al. Critcria for the diagnosis of is. chemic vascular dementia proposed by the State of California Alzheimer Disease Diagnostic and Treatment Centers (ADDTC). Neurology 1992; 42:473-480.

24. McKeith IG, Perry RH, Fairbairn AF, et al. Operational criteria for senile dementia of Lewy body type (SDLT). Psychol Med 1992;22:911-922.

25. Laurila JV, Pitkala KH, Strandberg TE, Tilvis RS. Detection and documentation of dementia and delirium in acute geriatric wards. Gen Hosp Psychiatry 2004;26:31-35.

26. Marcantonio ER, Kicly DK, Simon SE, et al. Outcomes of older people admitted to postacute facilities with delirium. J Am Geriatr Soe 2005; 53:963-969.
27. Sternberg SA, Wolfson C, Baungarten M. Undetected dementia in community dwelling older people: The Canadian Study of Health and Aging, J Am Geriatr Soc 2000;48:1430-1434.

28. Buila CJ, Wietlisbach V. Use of the Cognitive Performance Scale (CPS) to detect cognitlve Impairment in the acute care setting: Concurrent and predictive validity. Brain Res Bull 2009;80:173-178.

29. Knopman DS. The inltial recognition and diagnosis of dementia. Am J Med 1998;104:2S-12S.

30. Woods RT, Moniz-Cook E, Illiffe S, et al. Dementia: Issues in early recognition and intervention in primary care, J R Soc Med 2003;96 $320-324$.

31. Olafsdottir $M$, Foldevi $M$, Marcusson J. Dementia in primary care: Why the low detection ratel Scand J Prim Health Care 2001;19: $194-198$.

32. Kicly DK, Bergmann MA, Murphy KM, et al. Dellrium among newly admitted postacute facility patients: Prevalence, symptoms, and severity. J Gerontol A Biol Sci Med Sci 2003;58:M441-M445. 